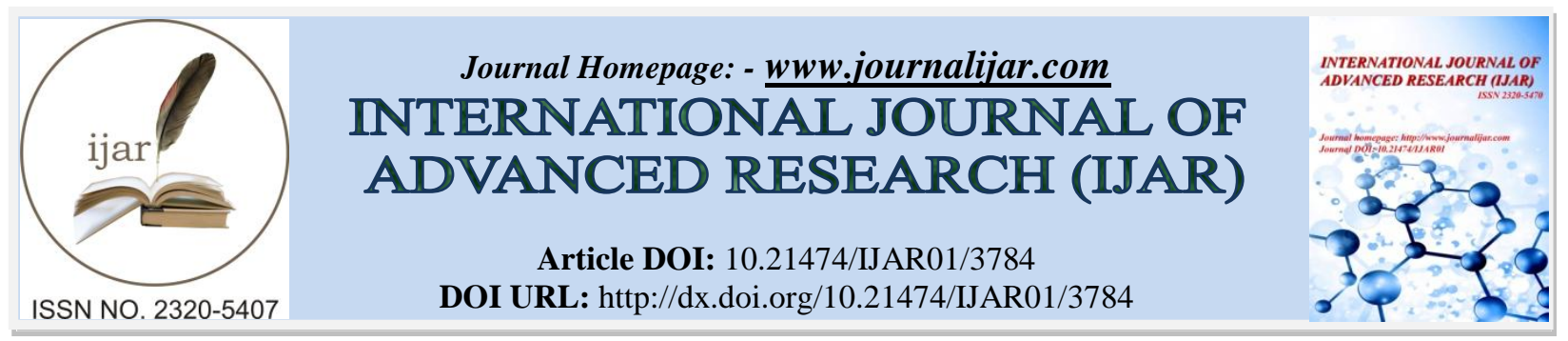

RESEARCH ARTICLE

\title{
THE EFFECT OF SLEEP ON CONCENTRATION AMONG HIGH SCHOOL STUDENTS AT ALRIYADH.
}

Hind Musfer Alghamdi, Afnan Abdullah Alghamdi, Dina Khaled Alhajri, Ghady Ibrahim Alhayazee, Lujain Hamad Alfayez, Nouf Abdullmohsen Albejadi, Nourah Abdulrahman Almoqbel, Rehab Mohammaed Aldossari, Shoug Fahad Algoblan, Waad Khalid Almusailhi and Waad Mohammed Awadh.

\section{Manuscript Info}

Manuscript History

Received: 01 February 2017

Final Accepted: 02 March 2017

Published: April 2017

\section{Abstract}

Objectives:- The aim is to know sleep phases and its patterns, including average sleeping hours and day naps during weekdays and weekends, sleep quality and sleep type. And knowing the different factors, which affect sleep, it includes alerts intake, lights, stresses and exercise.

Methods:- A cross sectional descriptive study was carried out in a high school, at AL Riyadh in April 2015. Ninety female students were interviewed using a specially constructed questionnaire. SPSS was used for data entry and analysis.

Results:- Normal sleep hours during weekdays were the practice of $47.8 \%$ of the participants. Good to excellent quality of sleep prevailed in $87.8 \%$ of them. Of those who frequently took caffeinated drinks, $60 \%$ had normal sleeping duration compared to $23 \%$ of those who infrequently did so. The difference was statistically significant $(\mathrm{p}=0.0017)$. Students with good attendance had significantly better grades than those with poor attendance $(p=0.0274)$. About $42 \%$ of those who were never/rarely sleepy during classes scored A, compared to about $24 \%$ of the girls who always/sometimes feel sleepy. The difference did not reach statistical significance.

Conclusion:- In this study poor school achievement was associated with excessive daytime sleepiness and poor school attendance. Sleep/wake pattern in this study did not show relationship with academic performance. Contrary to many studies, consumption of caffeinated drinks was associated with sleep duration.

Copy Right, IJAR, 2017,. All rights reserved.

\section{Introduction:-}

It is the ability to direct one's attention in accordance with one's well. It means control of the attention. It is the ability to focus the mind on one subject, object or thought, and at the same time exclude from the mind every other unrelated thoughts, ideas, feelings and sensations.(1)

A condition of body and mind, which typically recurs for several hours every night, in which the nervous system is inactive. The eyes are closed, the postural muscles relaxed, and consciousness practically suspended.(2) 
In the normal adult there are two main stages of sleep that alternate at about 90 minutes intervals. Rapid Eye Movement (REM) sleep can roughly described as a period when the brain is active and the body is paralyzed ( except for eye movements, middle ear ossicles, and respiration). In non-rapid eye movement (non-REM or NREM) sleep, the brain is less active but the body can move. Non-REM sleep is composed of four stages that are differentiated on the basis of EEG characteristics. When normal individuals first fall asleep, they enter Stage 1 (sleep drowsiness) and then progress through Stages 2, 3, and 4 of NREM sleep. Stages 3 and 4 (deep sleep) are often called slow wave sleep or delta sleep because they are characterized by high amplitude, slows waves (also called delta waves) on EEG. Slow wave sleep may last from a few minutes to an hour, depending on the person's age, before reversion back to Stage 2 sleep. Shortly after this, the first REM sleep period begins, lasting about 15-20 minutes and is followed by another non-REM cycle. This alternating pattern continues throughout the night, but as the night progresses Stages 3 and 4 are less apparent and the periods of REM sleep grow longer.(3)

The internal mechanisms that regulate almost ceaseless cycles of sleep and wakefulness make up a remarkable system. However, a variety of internal and external factors can dramatically influence the balance of this sleep-wake system.

Changes in the structure and function of the brain during development can have profound, if gradual, effects on sleep patterns. The amount of sleep obtained generally decreases and becomes more fragmented throughout lifespan. Other factors that affect sleep include stress and many medical conditions, especially those that cause chronic pain or other discomfort. External factors, such as eating and drinking, the medications taken. The environment can also greatly affect the quantity and quality of sleep. In general, all of these factors tend to increase the number of awakenings and limit the depth of sleep. (3)

Sleepiness slows down thought processes. Scientists measuring sleepiness have found that sleep deprivation leads to lower alertness and concentration. It's more difficult to focus and pay attention, so the student will be easily confused. This hampers the ability to perform tasks that require logical reasoning or complex thought. Sleepiness also impairs judgment. Making decisions is more difficult because the brain can't assess situation as well and pick the right behaviour. Poor sleep makes learning difficult.

Sleep deprivation affects ability to learn in 2 ways. For sure, focusing will be decreased and it's more difficult to pick up information so learning won't be efficient enough. It also affects memory, which is essential to learning. In children, sleepiness can lead to learning. Teens may lose the focus and memory capacity to perform well in school. (4)

\section{Objectives:-}

- To describe sleeping patterns among high school students.

- To identify the factors that affect sleep patterns.

- To study relationship between the sleep pattern and concentration.

\section{Literature Review:-}

In 2005 a study had done by Hansen, Illinois, USA. Was initiated to examine the impact of starting school on adolescent sleep, to compare weekday and weekend sleep times, and to attempt to normalize the timing of the circadian sleep/wake cycle by administering bright light in the morning. A survey among 2500 high-school students. Adolescents lost as much as 120 minutes of sleep per night during the week after the start of school, and weekend sleep time was also significantly longer (approximately 30 minutes) than that seen before the start of school (August). No significant differences were found between weekday sleep in the summer and weekend sleep during the school year. Early-morning light treatments did not modify total minutes of sleep per night, mood, or computeradministered vigilance test results. All students performed better in the afternoon than in the morning. Students in early morning classes reported being wearier, being less alert, and having to expend greater effort.(5)

In a study done by Wolsfon , 2000 , USA.The objective was to describe the relation between adolescents' sleep/wake habits, characteristics of students (age, sex, school), and daytime functioning (mood, school performance, and behavior) A Survey among 3,120 high school students. Self-reported total sleep times (school and weekend nights) decreased by 40-50 min across ages 13-19. The sleep loss was due to increasingly later bedtimes, whereas rise times were more consistent across ages. Students who described themselves as struggling or failing school (C's, D's/F's) reported that on school nights they obtain about 25 min less sleep and go to bed an 
average of 40 min later than A and B students. In addition, students with worse grades reported greater weekend delays of sleep schedule than did those with better grades. Altogether, most of the adolescents surveyed do not get enough sleep, and their sleep loss interferes with daytime functioning.(6)

Dr.Afandi, in Ajman (UAE), 2012, aimed to identify the factors affecting quality of sleep, and assess the impact of low quality sleep on the daily activities of students. Sleep quality was assessed. The result was that out of 290 students, they found $67.2 \%$ of students suffered from poor sleep and found that $62 \%$ of the students who never missed any class had a good sleep pattern, what indicates that poor sleep quality was strongly associated with higher anxiety level, and more morning classes missed. Most students suffer from poor sleep quality which is directly influencing behavior and anxiety levels. (7)

In a study done by Merdad in Jeddah 2014. She aimed to investigate the sleep-wake patterns, prevalence of excessive daytime sleepiness (EDS), and disturbed sleep among adolescents in Saudi Arabia and to identify the associated factors. The sample of the study of 1035 high school students, ages 14-23 years.the study shows that Adolescents suffers dramatically of poor sleep pattern. The Final result of this study Students slept an average of 7.0 hours on school nights, with an average delay of 2.8 and 6.0 hours in weekend sleep and rise times, respectively. Around 1 in 10 students stayed up all night and slept after returning from school (exhibiting a reversed sleep cycle) on weeknights. As a consequence of that poor mental health appears, as well as poor school academic performance. Also, poor school achievement appears in conjunction with excessive daytime sleepiness. (8)

In 2005, a study done by Yang aimed to detect changes in sleep/wake patterns on 1457 students, in Korea. It found that the higher the grade, the later bedtime was found to be on both schooldays and weekends. There was a similar relationship between increasing grade and earlier wake time on school days, but higher grades were associated with later wake time on weekends. Total sleep time decreased by approximately 3 hours on school nights and 1 hour on weekend nights from grades 5 to 12 . Adolescents were severely sleep deprived, with mean school-night total sleep times of $6.02,5.62$, and 4.86 hours for 10th-, 11th-, and 12th-graders, respectively. In the higher grades, there was a greater discrepancy between school nights and weekends in terms of bedtime and wake time, and the magnitude of weekend oversleep increased. Older students also reported more daytime sleepiness, more sleep/wakeproblem behavior, more depressed mood, and more eveningness preference. The chief reasons students cited for their sleep deprivation differed across grades: Academic demands and entertainment (such as Internet and television) were reported by 5th- and 6th-graders, entertainment and then academic demands by 7th-, 8th-, and 9thgraders, and early school start time and academic demands by 10th-, 11th- and 12th-graders. (9)

In 2014, A study done by Pereira, Brazil. The aim study was to investigate the associations between the type of transportation and travel time to school, the time in bed and sleepiness in the classroom of high school students. The study done on 1126 female student with an average age of 16 years. The time in bed was inversely associated with the travel time. In the adjusted analysis, active travel was more incident for the students of schools in the suburbs. in comparison with the students of schools in the center. Therefore, longer trips were associated with a reduction of sleep duration of morning and night groups. (10)

In a s study at Negra aim to to evaluate the association between environmental factors, sleep duration, and sleep bruxism (SB) in Brazilian. This study done on sample of of 120 adolescent with bruxism and 240 without bruxism, ages 17-20. The final result found that adolescent with a median sleep time $\leqslant 8$ hours per night who did not enjoy a good night's and slept with noise in the room were more likely to have SB. Light and noise in the room were two predisposing factors for the occurrence of SB. (11)

Study done by Veronica at 2001 - To evaluate the association between sleep disturbance and academic performance in children. From 1999 to 2001, the researchers distributed 5,400 questionnaires asking about symptoms of sleep disorders and sleep breathing disorders to children. Age seven to 10 who attended Sao Paulo public schools. They found that about $31 \%$ of the children had symptoms of sleep disorders - such as difficulty falling or staying asleep, or feeling sleepy all the time - and close to $27 \%$ had sleep breathing disorders. They result that on average kids with symptoms of sleep disorders or sleep breathing disorders earned lower grades than those without problems sleeping.. Those students' grades were significantly lower than the grades of kids without sleep disorder symptoms. (12) 
A study done b Pagel and it is published at 2010 in Colorado, Pueblo, CO, USA. He aimed to study the association between disordered sleep and school performance. Three samples of 3178 students were analyzed for that study: middle school (grades 6-8), high school (grades 9-11) and college students. That study shows clear association exists between reports of sleep disturbance and poor school performance. That study suggests that sleep disturbance negatively affecting student performance varies based on age and educational level. Reported restless legs and periodic limb movements are associated with lower GPA(grade point average) in junior high students, daytime sleepiness negatively affects high school students, and sleep onset and maintenance insomnia are significantly correlated with poorer school performance in college students. Impaired waking concentration is the likely waking correlate of sleep disturbance that negatively affects school performance. (13)

A study done by Chol sin in Korea in 2003 .The sample size of study are 4781 students in 11th grade from each of 10 schools. The purpose of the study was to assess sleep habits and Excessive Daytime Sleepiness(EDS), and its association with school performance in senior high school students in Korea. The result shows the prevalence of EDS in moderate grade students significantly higher than those with high grade students. moreover, the prevalence of EDS in male students significantly increased with a decline in school performance. The highest prevalence of EDS was also shown in female students with a low grade. (14)

Companionable sleep: Social regulation of sleep and co-sleeping in Egyptian families. in 2007; by Worthman. Participants comprised 78 members of 16 families from two locales in Egypt, Cairo and village between age of 2-60 years old. This exploratory study examines family sleep patterns and quality in a setting of normative napping and co-sleeping. Egyptian families exhibited the anticipated pattern of bimodal sleep, with the major sleep event at night and a nap in the afternoon Findings and other evidence suggest that such benefits occur at any age, important developmental task of emotional-cognitive maturation at adolescence is highly sensitive to sleep quality and sufficiency. They emphasize that such maturation also is sensitive to social context, including that of sleep. (15)

\section{Methodology:- \\ Study design:-}

The study was an observational descriptive cross-sectional school based survey.

\section{Study area and population:-}

It was done at al-Salam private high school, al-Rahmanyah neighborhood, at the north side of Al-Riyadh, KSA . The study population was of 300 female students.

\section{Sample technique and size:-}

A random sample of 90 female high school students, 30 student from each grade in different classes, ages (16-18) years, excluding the absent ones.

\section{Data needs:-}

The data collected by constructed questionnaire. It was divided into four parts including personal information, sleep phases, factors affecting sleep and concentration and lastly a part concerning the academic performance. The questionnaire was checked before conducting study for validity and reliability and then distributed among students.

\section{Data Analysis:-}

After questionnaires were filled by students, collected data has been cleared, coded, entered and analyzed by SPSS.

\section{Ethical issues:-}

The consent from school administration, then the permission has been taken verbally from students. Confidentiality was promised and maintained. 
Time line.

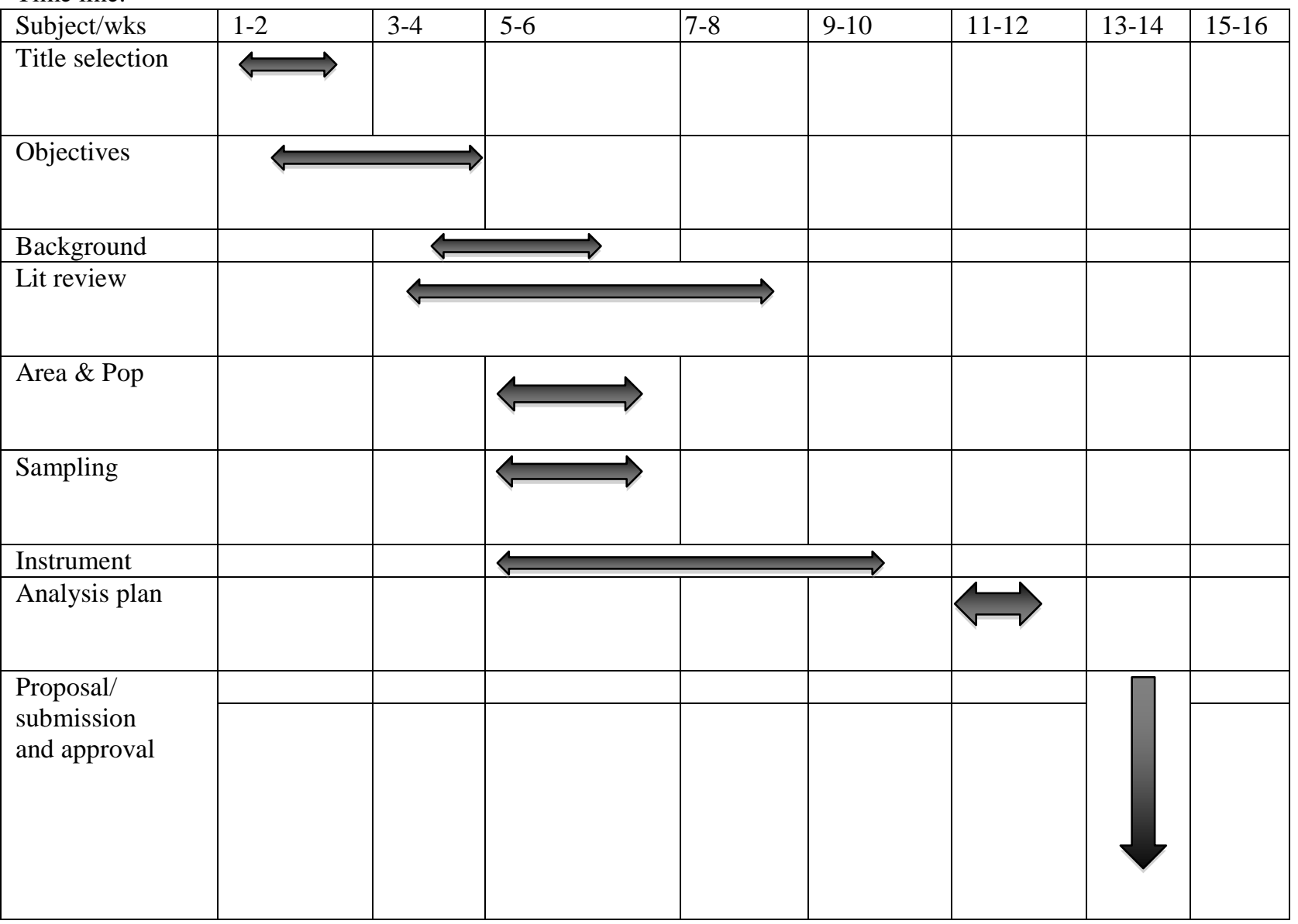

\section{Results:-}

The study conducted at Dar Alsalam High School in Riyadh aim to evaluate the effect of sleep on concentration among high school students. The data was obtained by questionnaire filled by 90 student, 30 student per each grade.

Table 1:- sleep in week days.

\begin{tabular}{|c|c|c|c|}
\hline \multicolumn{2}{|c|}{} & Frequency & Percent \\
\hline \multirow{4}{*}{ Less than 6 hours } & 21 & 23.3 \\
\cline { 2 - 4 } & 6-8 hours & $\mathbf{4 3}$ & $\mathbf{4 7 . 8}$ \\
\cline { 2 - 4 } & More than 8 hours & 26 & 28.9 \\
\hline Total & 90 & 100.0 \\
\hline
\end{tabular}

It was found 43 out of 90 students have normal sleep hours in week days which represent $47.8 \%$ of students.

Table 2: sleep hour in weekends

\begin{tabular}{|c|c|c|c|}
\hline \multicolumn{2}{|c|}{} & Frequency & Percent \\
\hline \multirow{4}{*}{} & less than 6 hours & 4 & 4.4 \\
\cline { 2 - 4 } & 6-8 hours & 22 & 24.4 \\
\cline { 2 - 4 } & More than 8 hours & $\mathbf{6 4}$ & $\mathbf{7 1 . 1}$ \\
\cline { 2 - 4 } & Total & 90 & 100.0 \\
\hline
\end{tabular}

The result shows 64 out of 90 sleep more than 8 hours in weekend which represent $71.1 \%$ of students. 
Table 3:- sleep quality.

\begin{tabular}{|c|c|c|c|}
\hline & Frequency & Percent \\
\hline \multirow{4}{*}{} & Excellent & 15 & 16.7 \\
\cline { 2 - 4 } & Very good & 25 & 27.8 \\
\cline { 2 - 4 } & good & $\mathbf{3 9}$ & $\mathbf{4 3 . 3}$ \\
\cline { 2 - 4 } & bad & 11 & 12.2 \\
\hline
\end{tabular}

It have been discovered 39 student have a good sleep quality which represent $43.3 \%$ of students.

The result is 52 out of 90 students get in into deep sleep which represent $57.8 \%$.

Table 4:- day nap (week days).

\begin{tabular}{|c|c|c|c|}
\hline & Frequency & Percent \\
\hline \multirow{4}{*}{} & always & $\mathbf{3 4}$ & $\mathbf{3 7 . 8}$ \\
\cline { 2 - 4 } & Sometime & 32 & 35.6 \\
\cline { 2 - 4 } & rarely & 15 & 16.7 \\
\cline { 2 - 4 } & never & $\mathbf{9}$ & $\mathbf{1 0 . 0}$ \\
\cline { 2 - 4 } & Total & 90 & 100.0 \\
\hline
\end{tabular}

We discover 34 out of 90 students always take a day nap on week day which represent $37.8 \%$ while 9 out of 90 students never take a day nap on week day which represent $10 \%$.

Table 5:- day nap (weekends).

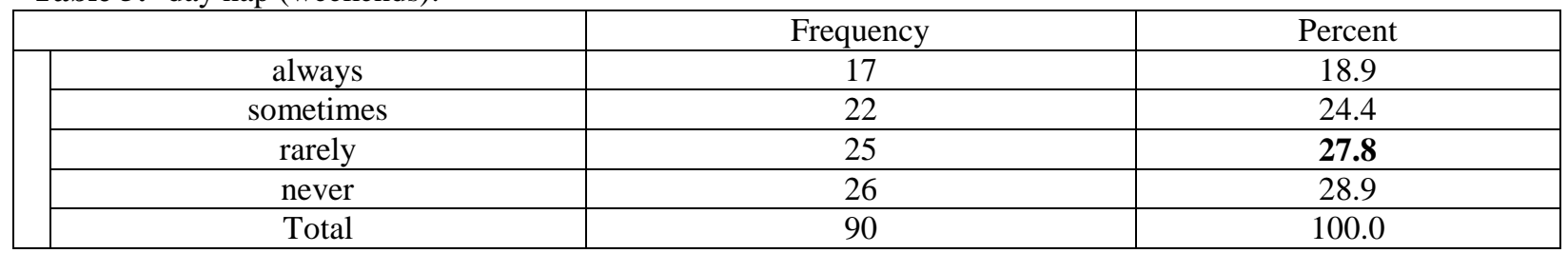

We discover 26 out of 90 students never take a day nap on weekend, which represent $28.9 \%$

The study showed 76 out of 90 students independently go to bed, which represents $84.4 \%$.

Table 6:-

\begin{tabular}{|c|c|c|c|c|c|}
\hline & & \multicolumn{3}{|c|}{ grade } & \multirow[t]{2}{*}{ Total } \\
\hline & & 1 & 2 & 3 & \\
\hline \multirow{3}{*}{$\begin{array}{c}\text { Sleep hours in } \\
\text { weekdays }\end{array}$} & Less than 6 hours & 6 & 9 & 6 & 21 \\
\hline & 6-8 hours & 13 & 15 & 15 & 43 \\
\hline & More than 8 hours & 11 & 6 & 9 & 26 \\
\hline \multirow{3}{*}{$\begin{array}{l}\text { sleep hour in } \\
\text { weekend }\end{array}$} & Less than 6 hours & 1 & 1 & 2 & 4 \\
\hline & 6-8 hours & 8 & 8 & 6 & 22 \\
\hline & More than 8 hours & 21 & 21 & 22 & 64 \\
\hline
\end{tabular}

It was discovered $47.7 \%$ of students have normal sleeping hours in week days, $14.4 \%$ of students were in the first grade, and it was found second and third grade have the same percentage of students which was $16.6 \%$. And found $24.4 \%$ of students have normal sleeping hours in weekends, and it was found first and second grade have the same percentage of students which was $8.8 \%$, and $6.6 \%$ of third grade students. Also it has been noticed no difference between sleeping hours in weekdays and weekends with the grade. 
Table 7:-

\begin{tabular}{|c|c|c|c|c|c|}
\hline & \multicolumn{3}{|c|}{ sleep hours in weekdays } & \multirow[t]{2}{*}{ Total } \\
\hline & & $\begin{array}{c}\text { Less than } 6 \\
\text { hours }\end{array}$ & 6-8 hours & $\begin{array}{c}\text { More than } 8 \\
\text { hours }\end{array}$ & \\
\hline \multirow[t]{4}{*}{ nightmares } & always & 0 & 1 & 0 & 1 \\
\hline & usually & 1 & 1 & 4 & 6 \\
\hline & sometimes & 10 & 25 & 10 & 45 \\
\hline & never & 10 & 16 & 12 & 38 \\
\hline \multirow[t]{4}{*}{ caffeinated drinks } & always & 5 & 11 & 7 & 23 \\
\hline & sometimes & 8 & 25 & 4 & 37 \\
\hline & Rarely & 5 & 4 & 9 & 18 \\
\hline & never & 3 & 3 & 6 & 12 \\
\hline \multirow[t]{4}{*}{ light on } & always & 2 & 9 & 3 & 14 \\
\hline & sometimes & 2 & 5 & 8 & 15 \\
\hline & Rarely & 5 & 11 & 2 & 18 \\
\hline & never & 12 & 18 & 13 & 43 \\
\hline \multirow[t]{4}{*}{ stress } & always & 13 & 23 & 16 & 52 \\
\hline & usually & 7 & 17 & 9 & 33 \\
\hline & Rarely & 1 & 1 & 1 & 3 \\
\hline & never & 0 & 2 & 0 & 2 \\
\hline \multirow[t]{4}{*}{ homeworks } & always & 5 & 14 & 5 & 24 \\
\hline & sometimes & 6 & 20 & 9 & 35 \\
\hline & Rarely & 7 & 3 & 10 & 20 \\
\hline & never & 3 & 6 & 2 & 11 \\
\hline \multirow[t]{2}{*}{ doing exercise } & yes & 7 & 5 & 5 & 17 \\
\hline & no & 14 & 38 & 21 & 73 \\
\hline
\end{tabular}

It was found $60 \%$ of students who always/sometimes drink caffeinated drinks had normal sleeping hours, also, $23 \%$ of students who rarely/never drink caffeinated drinks had normal sleeping hours which was statistically significant difference $(\mathrm{P}=0.0022)$.

A variation was found in the following, 50\% of student who sometimes/never had nightmares had normal sleeping hours $.42 \%$ of students who never sleep with light on had normal sleeping hours. Although $44 \%$ of students who always have stresses have normal sleeping hours. Also $57 \%$ of students who sometimes have a load of homework had normal sleeping hours. And $52 \%$ of students who don't do exercise before sleep, have normal sleeping hours in weekdays.

Table 8:-

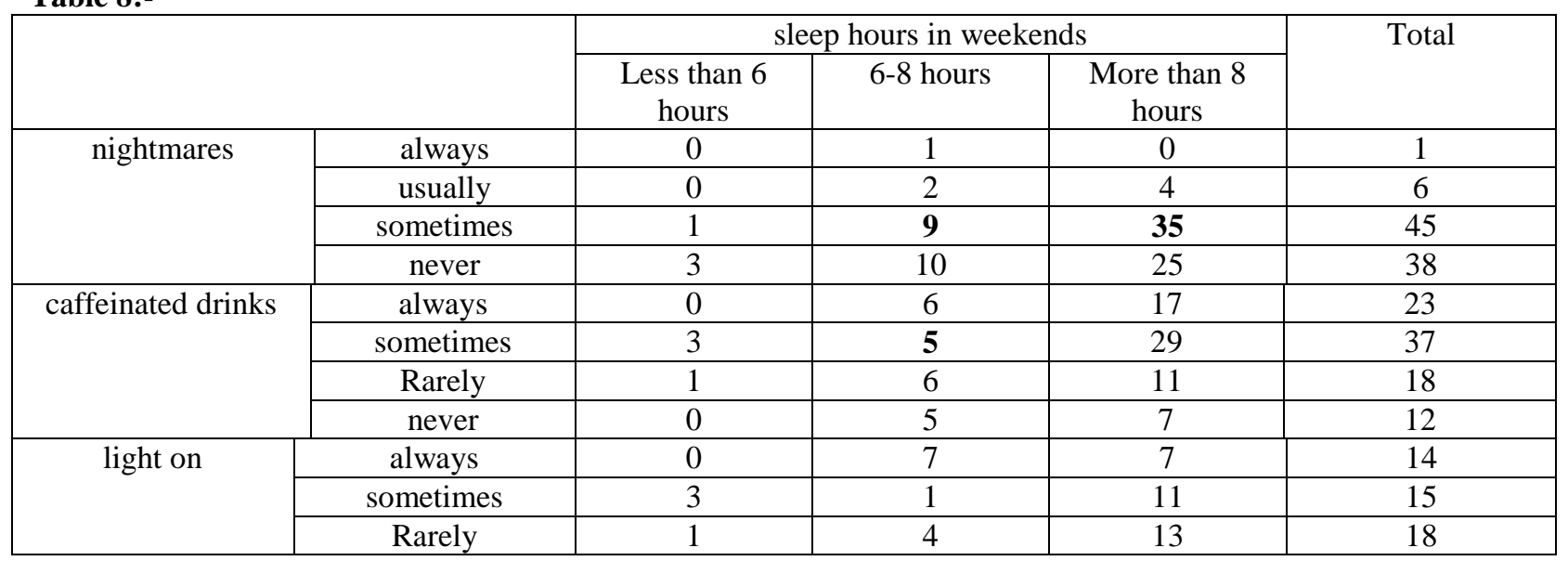




\begin{tabular}{|c|c|c|c|c|c|}
\hline & never & 0 & 10 & 33 & 43 \\
\hline \multirow[t]{4}{*}{ stress } & always & 2 & 14 & 36 & 52 \\
\hline & usually & 1 & 8 & 24 & 33 \\
\hline & Rarely & 0 & 0 & 3 & 3 \\
\hline & never & 1 & 0 & 1 & 2 \\
\hline \multirow[t]{4}{*}{ homeworks } & always & 1 & 6 & 17 & 24 \\
\hline & sometimes & 1 & 11 & 23 & 35 \\
\hline & Rarely & 1 & 4 & 15 & 20 \\
\hline & never & 1 & 1 & 9 & 11 \\
\hline \multirow[t]{2}{*}{ doing exercise } & yes & 1 & 3 & 13 & 17 \\
\hline & no & 3 & 19 & 51 & 73 \\
\hline
\end{tabular}

It was found $77 \%$ of students who sometimes have nightmares their average sleeping hours more than 8 hours, and $20 \%$ of students who sometimes have nightmares had normal sleeping hours in weekends. Also, $41 \%$ of students who never drink caffeinated drinks had normal sleeping hours. Moreover, 23\% of students who sleep with the light on had normal sleeping hours. And of $70 \%$ of students who always in stress have average sleeping hours of more than 8 hours. Although $66 \%$ of students who sometimes have a load of homework have average of sleeping hours more than 8 hours. However, 70\% of students who don't exercise before sleep have average sleeping hours of more than 8 hours. Which is a statistical variation with no statistical significance.

Table 9:-

\begin{tabular}{|c|c|c|c|c|c|c|c|}
\hline & \multicolumn{5}{|c|}{ percentage } & \multirow[t]{2}{*}{ Total } \\
\hline & & $\mathrm{A}$ & $\mathrm{B}$ & $\mathrm{C}$ & $\mathrm{D}$ & $\mathrm{F}$ & \\
\hline \multirow[t]{2}{*}{ attendance } & yes & 23 & 18 & 11 & 10 & 12 & 74 \\
\hline & no & 3 & 1 & 4 & 3 & 5 & 16 \\
\hline \multirow{4}{*}{$\begin{array}{c}\text { sleepiness } \\
\text { during class }\end{array}$} & always & 4 & 4 & 1 & 6 & 3 & 18 \\
\hline & sometimes & 12 & 11 & 9 & 5 & 11 & 48 \\
\hline & Rarely & 8 & 1 & 5 & 2 & 3 & 19 \\
\hline & never & 2 & 3 & 0 & 0 & 0 & 5 \\
\hline
\end{tabular}

It was found $55 \%$ of students who attend classes score A or B grades, while $25 \%$ of students who don't attend classes score A or B grades. And The second results indicate $38 \%$ of students who always/sometimes sleep during class get $\mathrm{D}$ or $\mathrm{F}$ grades. Which showed a borderline significance between students who attend classes and got higher $\operatorname{marks}(\mathrm{P}=0.0338)$.

\section{References:-}

1. R Sasson. Successconsciousness. What is concentration. Have you ever wondered what is concentration and how to strengthen it?.2001.

2. batric,D. (2008). Definition of Sleep in Available: http://www.oxforddictionaries.com/definition/english/sleep. Last accessed 20th Oct 2014.

3. Lovell K and Liszewski C. Normal Sleep Patterns and Sleep Disorders . Neurobiology of Narcolepsy and Hypersomnia. 2007; 18: 581-588.

4. Peri C. What Lack of Sleep Does to Your Mind. Sleepiness can damage your judgment, work performance, mood, and safety. WebMD. 2005.

5. Hansen M, Janssen I, etal. The impact of school daily schedule on adolescent sleep. Sleep in Children: Developmental Changes in Sleep Patterns, Second Edition 2005; 115 (6):1555-61.

6. Wolfson A, Carskadon M. Sleep schedules and daytime functioning in adolescents. Pediatrics [PubMed] 2000; 69 (4): 875-87.

7. Afandi O, Hawi H, Mohammed L, etal. Sleep Quality Among Students: Evaluating the Impact of Smoking, Social Media Use, and Energy Drink Consumption on Sleep Quality and Anxiety. Biological Psychiatry Journal 2013; 5(6): 13

8. Merdad R, Merdad L, Nassif R, etal. Sleep habits in adolescents of Saudi Arabia; distinct patterns and extreme sleep schedules. Sleep 2014; 15 (11): 1370-1378. 
9. Yang C, Kim J, Patel S, etal. Age-related changes in sleep/wake patterns among Korean teenagers. Pediatrics 2005; 115 (1): 250-6.

10. Pereira, Moreno C, etal. Increased commuting to school time reduces sleep duration in adolescents. Chronobiol Int. 2014; 31 (1): 87-94.

11. Negra, Paiva, etal. Environmental factors, sleep duration, and sleep bruxism in Brazilian schoolchildren: a casecontrol study. J Clin Sleep Med 2014; 15 (2):236

12. veronica,A. (2001). Poor sleep tied to kids' lower academic performance. Available: http://www.reuters.com/article/2013/08/16/us-health-poor-sleep-idUSBRE97F0UA20130816. Last accessed 26 april 2015.Jan;111(1):42-6 .

13. Pagel, etal. Sleep Complaints Affecting School Performance at Different Educational Levels. Negative mood states and related factors in a sample of adolescent secondary school students in Barcelona [PubMed] 2010; 1 (125).

14. Shin C, Kim J, Lee S, etal. Sleep habits, excessive daytime sleepiness and school performance in high school students. Psychiatry and Clinical Neurosciences 2003; 57

15. Worthman C, Brown R. Companionable sleep: social regulation of sleep and cosleeping in Egyptian families. $J$ Fam Psychol [PubMed] 2007; 21 (1):124-35,

16. Yang C, Kim J, Patel S, etal. Age-related changes in sleep/wake patterns among Korean teenagers. Pediatrics 2005; 115 (1): 250-6.

17. division of sleep medicine, department of neurology, etal. Caffeine consumption and weekly sleep patterns in US seventh-, eighth-, and ninth-graders. Pediatrics. 2003 Jan;111(1):42-6 .

18. Shin C, Kim J, Lee S, etal. Sleep habits, excessive daytime sleepiness and school performance in high school students. Psychiatry and Clinical Neurosciences 2003; 57

19. Merdad R, Merdad L, Nassif R, etal. Sleep habits in adolescents of Saudi Arabia; distinct patterns and extreme sleep schedules. Sleep 2014; 15 (11): 1370-1378.

20. Stuart F Steven A, Laker M ,etal. External Factors that Influence Sleepm WGBH Educational Foundation for the Harvard Medical School Division of Sleep Medicine. 2006. How is Sleep Regulated.

21. Lodato $\mathrm{F}^{1}$, Araújo J, Barros H etal, Caffeine intake reduces sleep duration in adolescents. University of Porto Medical School, Porto, Portugal; Department GF Ingrassia, University of Catania, 2013 Sep;33(9):726-32.

22. Worthman C, Brown R. Companionable sleep: social regulation of sleep and cosleeping in Egyptian families. $J$ Fam Psychol [PubMed] 2007; 21 (1):124-35.

23. Kim Rachan. Weekday Versus Weekend Hours of Sleep.

24. Joliet Junior College [StatCrunch] 2012; 11(2):110-160.

\section{Questionnaire:-}

We are medical students in Alma'arefa college, we present you this questionnaire aiming to check the sleep in relation to academic performance in different levels, by studying factors effecting sleep and its patterns, we appreciate your participation and your confidentiality will be maintained.

Name of school:

1/Personal information:

Full name :

Age:

\begin{tabular}{l|ll}
\hline & Years. & Grade: 1
\end{tabular}

2/Sleep pattern:

1)A. How long do you sleep on weekdays (on average)? ............ Hours

B. What time do you go to bed weekdays? ........... O'clock

2)A. How long do you sleep on weekends? .............. Hours

B. What time do you go to bed weekdays? ............. O'clock

3) How often have you had trouble sleeping because ... 


\begin{tabular}{|l|l|l|l|l|}
\hline & Never & Sometimes & Usually & Always \\
\hline $\begin{array}{l}\text { A) cannot get to sleep within 30 minutes of } \\
\text { getting to bed. }\end{array}$ & & & & \\
\hline B) have nightmares. & & & & \\
\hline C) have insomnia. & & & & \\
\hline
\end{tabular}

4) Are you a deep sleeper?
A)Yes
B) No

3/Factors of sleep pattern :

\begin{tabular}{|l|l|l|l|l|}
\hline & Always & Frequently & Rarely & Never \\
\hline 1) I take daytime nap (weekend) & & & & \\
\hline 2) I take daytime nap (weekdays) & & & & \\
\hline 3) I take alerts (coffee, tea, etc. ) & & & & \\
\hline 4) I usually sleep with light turned on & & & & \\
\hline $\begin{array}{l}\text { 5) The days before exams I usually sleep late } \\
\text { and less hours }\end{array}$ & & & & \\
\hline 6) I have a lot of exams & & & & \\
\hline 7) I am overloaded with homework's & & & & \\
\hline 8) I take shower before I sleep & & & & \\
\hline 9)I exercise regularly & & & & \\
\hline 10) Do you recite Quran & & & & \\
\hline
\end{tabular}

4/ Relationship between concentration and sleep pattern :

1) Do you attend all classes ?

$\begin{array}{ll}\text { A) Yes } & \text { B) No }\end{array}$

2) Do you feel from sleepy during lesson?
A) Yes
B) $\mathrm{No}$

\section{Discussion:-}

The study was conducted to find out relationship between sleep pattern and academic performance, it was found that the caffeine intake and exercise were the main factors affecting sleep hence, the academic performance. The study also revealed that attendance and sleepiness during class in correlation to students final grade was of high statistical significance.

This study showed no difference between sleeping hours in weekdays and weekends in relation to the grade. In contrast, a study done by Yang in 2005 in Korea aimed to detect changes in sleep/wake patterns, It was found that the higher grades were in those who slept late at both weekdays and weekends but they woke up earlier at weekdays than weekends. (16)

According to this study, it was found the majority of students who always drank caffeinated drinks had normal sleeping hours which is opposite to a study conducted in Italy, when they found that drinking caffeinated drinks was inversely associated with sleep duration. This study showed that about more than the half of the students who didn't do exercise before sleep, had normal sleeping hours in weekdays. Which is different to a study done in Brazil, which found the opposite in the result. This study showed students who intake more caffeine sleep more hours during weekends. In 2003 in US, a study showed high caffeine intake in general was associated with shorter nocturnal sleep duration in weekend. Which contrast this study. (17)

The study showed those students who slept during classes scored low grade, which is compatible with result of a study done in Korea in 2003(18), also showed that poor school achievement appears in conjunction with excessive daytime sleepiness, similar to another study done in Jeddah 2014. (19)

This result showed that there was a significant relationship between attendance and students' academic achievement. Score for students with good attendance was higher than the needing improvement/poor attendance group, and this result is similar to a study had done by in USA in 2006. (20) 
This study showed students who intake more caffeine sleep more hours during weekends. In 2003 in US, a study showed high caffeine intake in general was associated with shorter nocturnal sleep duration in weekend. Which contrast this study.(21)

In this study it was found that afternoon napping occurred in less than half number of sample size. Which is similar to study done by Worthman, in 2007. It showed the anticipated two patterns of sleep, with the major sleep event at night and a nap in the afternoon Findings. (22)

This study showed the majority of the students have normal sleeping hours average of 8 hours on weekdays, while in weekend, more than half of the students sleep more than 8 hours. Which is similar to a study done in USA. (23)

\section{Conclusion:-}

In this study poor school achievement was associated with excessive daytime sleepiness and poor school attendance. Sleep/wake pattern in this study did not show relationship with academic performance. Contrary to many studies, consumption of caffeinated drinks was associated with sleep duration.

\section{Recommendations:-}

1. Set a regular bedtime and wakeup time, creating a habit of going to bed and waking up at the same time each day, even on weekends. This helps anchor your body clock to these times.

2. More studies should be conducted to know about the effect of caffeine drinks and other factors.

3. Steps should be taken to solve the problem of daytime sleeping which affecting academic performance.

4. Parents should have more control over sleeping time especially in weekdays. 